\title{
Xenobiotic metabolising enzyme expression in colonic neoplasia
}

\author{
J A McKay, G I Murray, R J Weaver, S W B Ewen, W T Melvin, M D Burke
}

\begin{abstract}
The cytochrome P450, epoxide hydrolase, and glutathione S-transferase enzyme families play an important part in the metabolism of many carcinogens and anti-cancer drugs. The expression of two forms of cytochrome P450 (P450 1A and P450 3A), epoxide hydrolase and of the $\alpha, \mu$, and $\pi$ forms of glutathione $S$-transferase in normal colon, colonic adenomas, and adenocarcinoma of the colon were studied by immunohistochemistry. This allowed the precise cellular site and distribution of each enzyme to be determined. Expression of all the xenobiotic metabolising enzymes studied was almost wholly confined to the epithelial cells, whether in normal, adenoma or carcinoma samples, except that cytochrome P450 3A was also identified in mast cells and glutathione $S$-transferase $\pi$ was also present in chronic inflammatory cells. Cytochrome P450 was present in only a small proportion of normal colon samples, whereas epoxide hydrolase and glutathione S-transferase $\mu$ were identified in about half, and glutathione S-transferase $\alpha$ and $\pi$ in most normal samples. By contrast all the enzyme forms studied were expressed in virtually all adenomas and in over half the carcinomas. These results suggest that cytochrome P450 1A and cytochrome P450 3A are more specific markers of colonic neoplasia than epoxide hydrolase or glutathione Stransferases $\alpha, \mu$, and $\pi$.

(Gut 1993; 34: 1234-1239)
\end{abstract}

Colon cancer is the most common malignant tumour of the gastrointestinal tract and is one of the commonest causes of death from cancer. Colonic carcinomas are often intrinsically resistant to anti-cancer drugs, and these tumours respond poorly to anti-cancer drugs. Recent evidence has shown that the expression of enzymes participating in biotransformation may play a part in tumour drug-resistance. ${ }^{12}$ Moreover, the same group of xenobiotic metabolising enzymes are probably involved in the development of colonic carcinoma. ${ }^{3-5}$

The colonic epithelium is in continuous contact with potentially carcinogenic compounds, which enter the body usually as part of the diet. These xenobiotics may be activated or detoxified by phase I and phase II biotransformation enzymes including cytochromes $\mathbf{P} 450$, epoxide hydrolases, and glutathione S-transferases. ${ }^{67}$ Metabolism may occur in the gastrointestinal tract, including the colon or in the liver, or both.

Cytochromes $\mathrm{P} 450$ are a multi-gene superfamily of haem containing enzymes that catalyse the oxidative metabolism of many compounds. Their substrates are endogenous compounds such as steroids and prostaglandins as well as many xenobiotics such as carcinogens, mutagens, and drugs including anti-cancer drugs. ${ }^{8-11}$ Cytochrome P450 metabolism of compounds may result in either activation or detoxification.

The main cytochromes $\mathrm{P} 450$ participating in the metabolism of xenobiotics are families 1, 2, and 3 , which are primarily located within the liver, although specific forms of cytochrome P450 are expressed in particular extrahepatic tissues. For example, members of the cytochrome P450 family 3 are present in high concentration in small intestinal epithelium and it has been suggested that they protect the small intestine from carcinoma. $^{12}$ Indeed, it has recently been suggested that an absence from the colon of certain of these enzymes, especially specific forms of cytochrome P450, may be involved in the comparatively high incidence rate of carcinogenesis in this organ. ${ }^{13}$

One type of product of cytochrome P450 mediated metabolism are potentially toxic epoxides. These can be converted to comparatively less toxic trans-dihydrodiols by a group of enzymes known as epoxide hydrolases, ${ }^{14}$ although subsequent oxidation can lead to the formation of diol epoxide derivatives, which are more toxic than their parent compounds. Epoxide hydrolases are mainly located within the smooth endoplasmic reticulum (microsomal fraction of subcellular homogenate).

Toxic electrophilic compounds produced by both cytochromes P450 and microsomal epoxide hydrolases can be eliminated from the body by conjugation with glutathione. This conjugation reaction is catalysed by another complex gene family, the glutathione S-transferases. The three main groups of glutathione S-transferases are $\alpha$ (basic), $\mu$ (neutral), and $\pi$ (acidic), mainly present in the liver, but also present in various extrahepatic tissues ${ }^{15}$ including intestinal epithelium. Recent studies have suggested an increased activity of expression of glutathione S-transferases in colonic tumour cells compared with normal non-neoplastic mucosa. ${ }^{16}$

As the expression of different xenobiotic metabolising enzymes may take part in both the development of colonic neoplasia and drug resistance of established colonic carcinomas we have investigated the expression of cytochromes P450 $1 \mathrm{~A}$ and $3 \mathrm{~A}$, epoxide hydrolase, and glutathione $S$-transferases $\alpha, \mu$, and $\pi$ in normal colon, colonic adenomas, and adenocarcinoma of the colon.

\section{Methods}

\section{ANTIBODIES}

Cytochrome P450 1A was identified using a murine monoclonal antibody (RM3) as des- 
cribed previously. ${ }^{17}$ Cytochrome P450 3A was also identified using a monoclonal antibody (HL3), which has been raised and characterised in our laboratories. ${ }^{1819}$ Microsomal epoxide hydrolase was recognised using a rabbit polyclonal antibody raised in our laboratories against a purified preparation of human hepatic microsomal epoxide hydrolase.$^{20}$ Cytoplasmic forms of glutathione $\mathrm{S}$-transferases $\alpha, \mu$, and $\pi$ were recognised using rabbit polyclonal antibodies purchased from Novocastra Laboratories, Newcastle upon Tyne. All the antibodies used in this study recognise epitopes that are resistant to formalin fixation and wax embedding.

TISSUE

Specimens of normal colon, colonic adenoma, and colon carcinoma were obtained from biopsies and resected specimens submitted to the Department of Pathology, University of Aberdeen, for diagnostic purposes. Biopsy specimens of normal colon were obtained from patients without any evidence of colonic neoplasia. All the tissue samples had been fixed in $10 \%$ neutral buffered formalin for 24 hours at room temperature and then routinely processed to paraffin wax. The colonic carcinomas were staged using Dukes's classification.

\section{IMMUNOHISTOCHEMISTRY}

Formalin fixed wax embedded sections $(4 \mathrm{~cm})$ of the colonic tissues were dewaxed in xylene, rehydrated in alcohol and spirit (95\% alcohol), each step being carried out for five minutes at room temperature, then washed in cold water. Before applying any immunochemicals, the sections were washed with $0.05 \mathrm{M}$ TRIS-HCl (pH 7.6) containing $0 \cdot 15 \mathrm{M}$ sodium chloride (TBS) for two successive five minute periods. Both negative and positive controls were incorporated in the immunohistochemical procedure. Negative controls used in place of the primary antibody were either TBS (control for monoclonal antibodies), or normal rabbit immunoglobulins (control for polyclonal antibodies). Positive controls were sections of normal formalin fixed wax embedded human liver as liver is known to express all the enzymes being studied.

The slides were examined using transmitted light microscopy to assess qualitatively the presence or absence of immunostaining, and its distribution.

Correlations between the expression of the different enzymes with tumour grade (Dukes's stages $A, B, C$ ) were measured by the $\chi^{2}$ test with Yates's correction.

Cytochrome P450 $1 \mathrm{~A}$ and cytochrome P450 3 A

Rehydrated tissue sections were incubated for one hour at room temperature with each of the monoclonal antibodies at the following dilutions: anti-cytochrome P450 1A, 1/20 dilution in TBS of a $50 \%$ ammonium sulphate precipitate of hybridoma culture supernatant, and anticytochrome $\mathrm{P} 450 \mathrm{AA}$ as undiluted hybridoma culture supernatant. Sites of antibody binding were shown with an alkaline phosphatase antialkaline phosphatase (APAAP) technique. ${ }^{21}$ This procedure entails the sequential incubation of rabbit anti-mouse immunoglobulin (1/100 containing 5\% normal human serum, Dako Ltd, High Wycombe, Bucks) and monoclonal APAAP (1/100, Dako) for 30 minutes each at room temperature. The sections were washed with TBS for two successive five minute periods after each incubation to remove unbound antibody. Sites of bound alkaline phosphatase were shown with a solution containing $3 \mathrm{mg}$ bromochloro-indolyl phosphate (Sigma Chemical Co Ltd, Poole, Dorset), $10 \mathrm{mg}$ nitro blue tetrazolium (Sigma), $6 \mathrm{mg}$ sodium azide, and $4 \mathrm{mg}$ levamisole (Sigma) in $10 \mathrm{ml} \mathrm{0.05} \mathrm{M} \mathrm{TRIS-HCl}$ buffer ( $\mathrm{pH} 9 \cdot 0$ ) containing $0 \cdot 2 \%$ magnesium chloride. After incubating for 30 minutes at room temperature, the reaction was stopped by washing the sections in cold water. The slides were then air.dried and mounted in glycerine jelly.

\section{Epoxide hydrolase and glutathione S-transferases}

Polyclonal anti-epoxide hydrolase antibody was applied to tissue sections at a dilution of $1 / 50$ of a stock $20 \mathrm{mg} / \mathrm{ml}$ solution, prepared from the lyophilate of a $50 \%$ ammonium sulphate precipitate of immunised rabbit serum. Polyclonal antibodies to the three classes of glutathione S-transferase were applied at the following dilutions of a stock solution (protein concentration $1 \mathrm{mg} / \mathrm{ml}$ ): glutathione S-transferase $\alpha 1 / 100$; glutathione $S$-transferase $\mu 1 / 50$; glutathione S-transferase $\pi 1 / 200$. Each of the antibodies were applied to tissue sections for one hour at room temperature, and the sites of bound antibody shown by the APAAP technique. After removal of unbound primary antibody, the sections were incubated with monoclonal mouse anti-rabbit immunoglobulin (1/100, Dako) for 30 minutes at room temperature before the application of rabbit anti-mouse immunoglobulin and APAAP complex. The sites of bound alkaline phosphatase were then shown as above.

TABLE I Number (percentage) of colonic samples expressing cytochrome P450 IA (P450 1A), cytochrome P450 3A (P450 $3 A)$, epoxide hydrolase $(E H)$, and glutathione $S$-transferases $\alpha, \mu$, and $\pi(G S T \alpha, G S T \mu$, and $G S T \pi)$

\begin{tabular}{lcll}
\hline Enzyme & $\begin{array}{l}\text { Normal } \\
(n=13)\end{array}$ & $\begin{array}{l}\text { Adenoma } \\
(n=12)\end{array}$ & $\begin{array}{l}\text { Carcinoma } \\
(n=28)\end{array}$ \\
\hline P450 1A & $0(0 \%)$ & $12(100 \%)$ & $21(75 \%)$ \\
P450 3A & $2(15 \%)$ & $12(100 \%)$ & $17(61 \%)$ \\
EH & $6(46 \%)$ & $12(100 \%)$ & $25(89 \%)$ \\
GST $\alpha$ & $10(77 \%)$ & $12(100 \%)$ & $20(71 \%)$ \\
GST $\mu$ & $6(46 \%)$ & $10(83 \%)$ & $17(61 \%)$ \\
GST $\pi$ & $10(77 \%)$ & $12(100 \%)$ & $17(61 \%)$ \\
\hline
\end{tabular}

TABLE II Number (percentage) of colonic samples expressing different numbers of enzymes

\begin{tabular}{llll}
\hline $\begin{array}{l}\text { No of enzymes } \\
\text { expressed }\end{array}$ & $\begin{array}{l}\text { Normal } \\
(n=13)\end{array}$ & $\begin{array}{l}\text { Adenoma } \\
(n=12)\end{array}$ & $\begin{array}{l}\text { Carcinoma } \\
(n=28)\end{array}$ \\
\hline 0 & $2(15 \%)$ & $0(0 \%)$ & $0(0 \%)$ \\
1 & $1(8 \%)$ & $0(0 \%)$ & $2(7 \%)$ \\
2 & $2(15 \%)$ & $0(0 \%)$ & $2(7 \%)$ \\
3 & $4(31 \%)$ & $0(0 \%)$ & $4(14 \%)$ \\
4 & $4(31 \%)$ & $0(0 \%)$ & $7(25 \%)$ \\
5 & $0(0 \%)$ & $2(17 \%)$ & $8(29 \%)$ \\
6 & $0(0 \%)$ & $10(83 \%)$ & $5(18 \%)$ \\
\hline
\end{tabular}




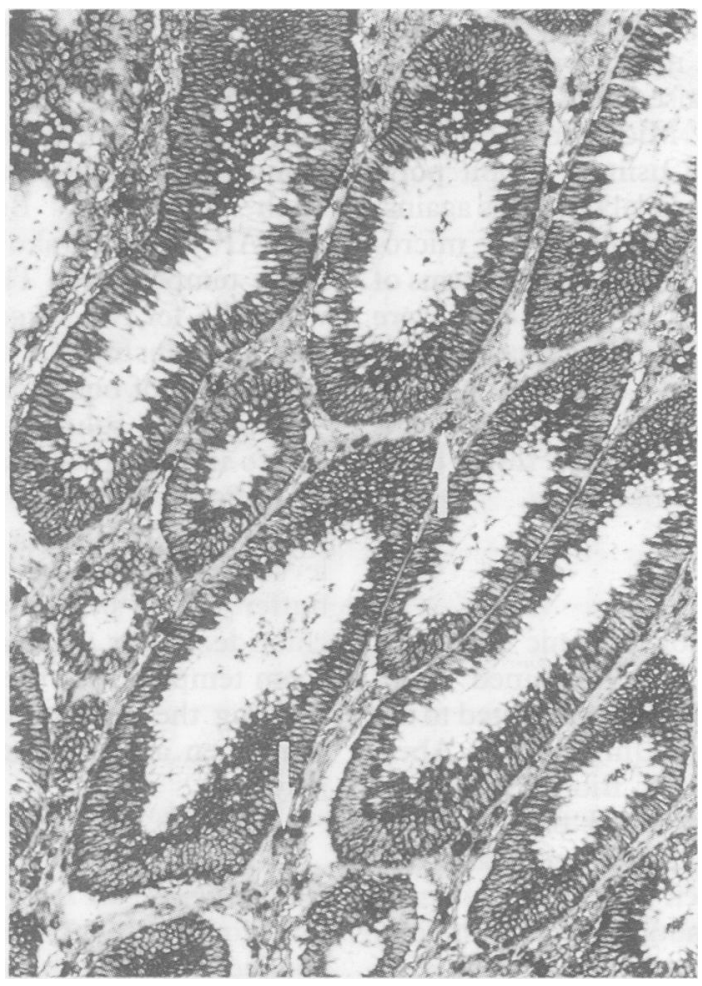

Figure 1: Cytochrome P450 $3 \mathrm{~A}$ immunoreactivity in a tubular colonic adenoma. Immunostaining is present in the cytoplasm of tumour cells and also mast cells (arrows) present in the stroma. (Original magnification $\times 100$.)

\section{Results}

NORMAL COLON

In all thirteen normal human colon biopsy specimens that were examined, immunoreactivity for each enzyme seemed to be patchy and focal on the surface of the colonic epithelium, with no immunostaining present in crypt epithelium. None of the biopsy specimens displayed positive immunoreactivity for cytochrome $\mathbf{P} 450$ $1 A$ and only two (15\%) of the samples displayed positive epithelial immunoreactivity for cytochrome $\mathrm{P} 450$ 3A. In addition, mast cells in normal colon, adenoma, or carcinoma samples consistently showed strong positive staining for cytochrome P450 3A. Six (46\%) of the biopsy specimens were found to show immunostaining for epoxide hydrolase in colonic epithelium. Immunoreactivity for glutathione S-transferases $\alpha$ and $\pi$ was present in $10(77 \%)$ of the samples, with glutathione $S$-transferase $\mu$ expressed in six (46\%, Table I). Glutathione S-transferase $\pi$ immunoreactivity was also identified in chronic inflammatory cells present in normal colon, adenoma, or carcinoma samples.

Negative controls did not show any immunostaining and the positive controls always showed positive and appropriate immunoreactivity with all the enzymes.

\section{COLONIC ADENOMAS}

Twelve colonic adenoma biopsy specimens were examined, of which six were tubular adenomas, three were villous adenomas, and three were tubulovillous adenomas. All $12(100 \%)$ were found to show positive immunostaining for both forms of cytochrome P450, cytochrome P450 $1 \mathrm{~A}$, and cytochrome P450 3A. This was also the case for three other enzymes, epoxide hydrolase, glutathione S-transferase $\alpha$, and glutathione $S$-transferase $\pi$, where all the tumours showed positive immunoreactivity. Glutathione S-transferase $\mu$, however, was expressed in $10(83 \%)$ of the tumours (Tables I and II).

For each enzyme, immunoreactivity was present in the cytoplasm of tumour cells (Fig 1). In areas of villous adenoma some of the tumour cells also showed nuclear immunoreactivity (Fig 2). Mucus secretory cells did not show any immunoreactivity.

\section{COLONIC CARCINOMAS}

Twenty eight colonic carcinoma tumours were examined, all of which were moderately differentiated adenocarcinomas. There were three Dukes's grade A carcinomas, 13 Dukes's grade B tumours, and 12 Dukes's grade $C$ adenocarcinomas. Based on immunoreactivity, all the carcinomas expressed at least one enzyme, and six tumours expressed all six enzymes (Table II).

Twenty one $(75 \%)$ of the carcinomas showed positive immunostaining for cytochrome P450 $1 \mathrm{~A}$, with $17(61 \%)$ showing positive immunostaining for cytochrome P450 3A. Epoxide hydrolase immunoreactivity was present in 25 $(89 \%)$ of the tumours, $20(71 \%)$ showed positive immunostaining for glutathione S-transferase $\alpha$, whereas both glutathione S-transferases $\mu$ and $\pi$ were detected in $17(61 \%)$ of the tumours (Table II).

Immunostaining for each enzyme was present in the cytoplasm of tumour cells (Figs 3 and 4), although in a few cases nuclear staining was also seen for the glutathione S-transferases. The

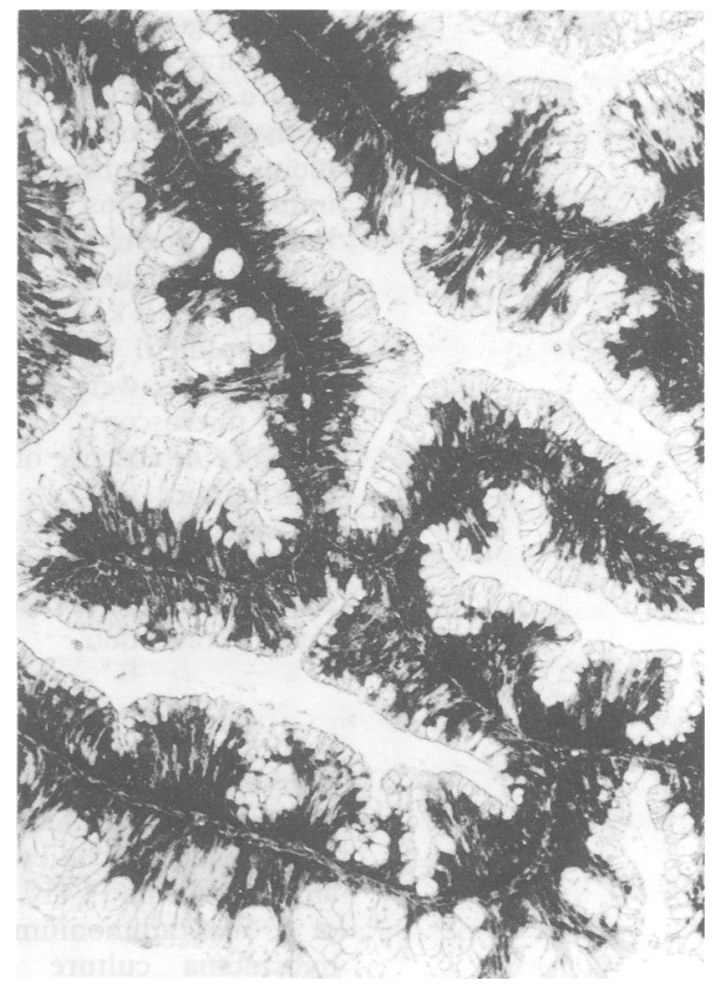

Figure 2: Glutathione $S$-transferase $\alpha$ immunoreactivity in a villous adenoma. (Original magnification $\times 100$.) 


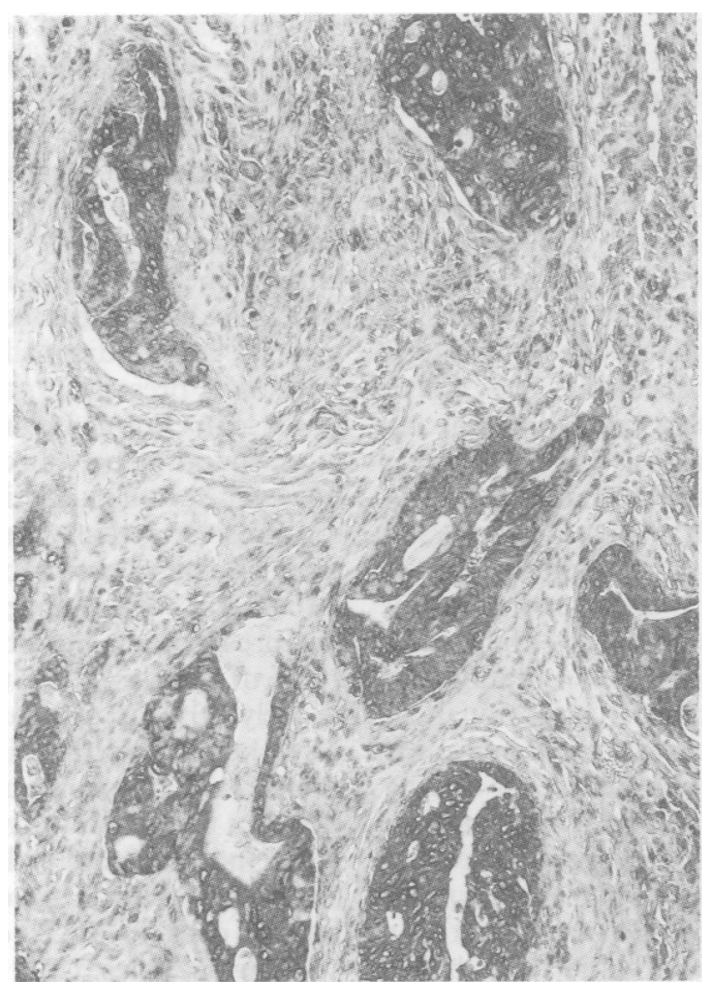

Figure 3: Cytochrome P450 1A expression in a moderately differentiated adenocarcinoma of colon. There is cytoplasmic immunostaining in all tumour cells (Original magnification $\times 100$.)

immunoreactivity for each enzyme seemed to be homogeneously distributed throughout each tumour.

There were no significant correlations between enzyme expression and Dukes's grade.

\section{Discussion}

The development of carcinoma of the colon is dependent on both genetic and environmental factors and its is generally accepted that the development of colonic carcinoma follows the adenoma-carcinoma sequence. The presence in the diet of carcinogens or pro-carcinogens is probably one important environmental factor and these carcinogens and pro-carcinogens can be either activated or deactivated by xenobiotic metabolising enzymes present in the colon. Some of these compounds may already have had metabolism in the liver or small intestine, or both, before reaching the colon by biliary excretion. We have studied the localisation by immunohistochemistry of different forms of the drug metabolising enzymes, cytochrome P450, epoxide hydrolase, and glutathione S-transferase in normal colon, and benign and malignant epithelial tumours of the colon.

Although there have been several biochemical investigations of cytochrome P450 and glutathione S-transferase in human colonic carcinomas, it is difficult to compare directly biochemical and immunohistochemical studies of enzymes, and both approaches have advantages and limitations. Biochemistry can be quantitative but immunohistochemistry is qualitative. Whereas biochemical studies can measure enzyme activities, immunohistochemistry can

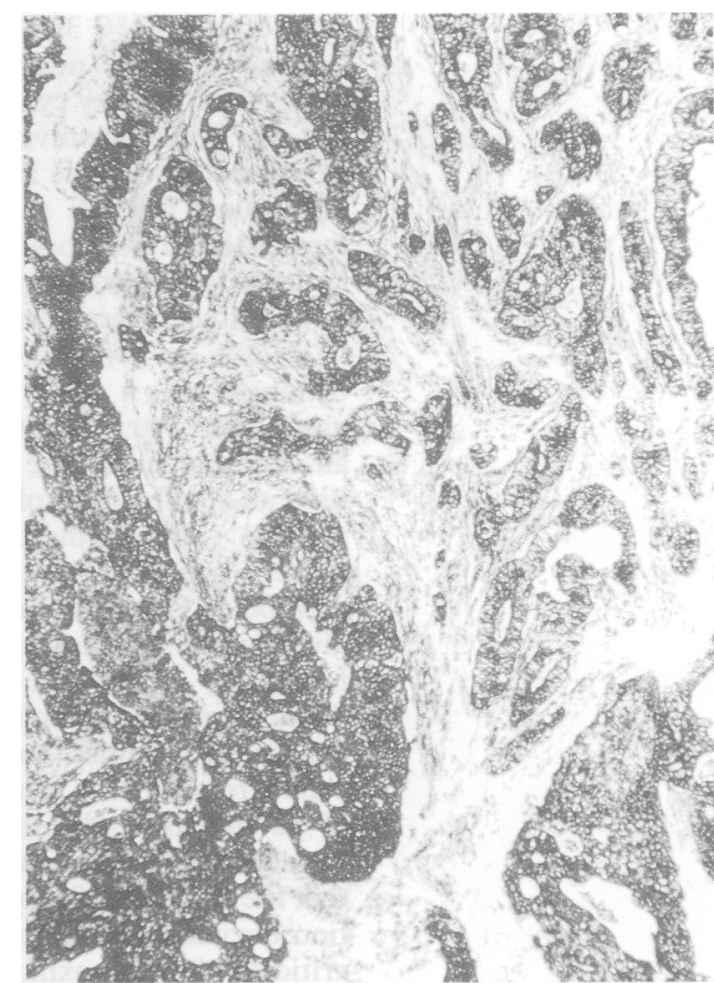

Figure 4: Epoxide hydrolase immunohistochemistry shows cytoplasmic immunoreactivity in tumour cells of a moderately differentiated adenocarcinoma of colon. (Original magnification $\times 40$.)

only provide information on enzyme protein, some of which may be inactive. Immunohistochemistry cannot distinguish between different immunologically cross reactive proteins, but biochemically these can often be differentiated according to molecular weight using immunoblotting. The overriding advantage of immunohistochemistry, however, is its ability to localise enzymes to individual cells in heterogeneous samples. This is crucial, as tumour samples are almost invariably mixtures of tumour cells, nontumour epithelium, connective tissue, and inflammatory cells, the proportions of which vary from one sample to another. Biochemical studies can provide only average values for enzymes activities amongst all the different cells in the tumour sample and, most importantly, cannot show whether an enzyme is present specifically in tumour cells. Several biochemical studies of xenobiotic metabolising enzymes in the colon have made comparisons between samples of normal and tumour tissue, but are of limited value as they take no account of the varying proportions of different types of enzyme expressing and nonexpressing cells in the samples.

Biochemical studies of normal colonic epithelium have shown that several different xenobiotic metabolising enzymes have a low activity in colonic epithelium. It should be noted, however, that several of these studies used non-tumour epithelium adjacent to colonic carcinomas and this epithelium may not be functioning normal. de Waziers et $a l^{22}$ reported the presence of a small amount of cytochrome $\mathrm{P} 4503 \mathrm{~A}$ in normal colon samples with a western blot procedure, and we have found immunohistochemically the presence of a member of the 
cytochrome P450 3A family in normal colonic epithelium while neither de Waziers nor ourselves detected any cytochrome P450 1A. There has only been one previous report of the presence of epoxide hydrolase in normal colonic tissue. ${ }^{22}$ We found that all three glutathione S-transferases tested were present in colonic epithelium and this is consistent with the findings of Howie et $a l^{23}$; it contrasts, however, with the results of Hayes et $a l,{ }^{24}$ who identified glutathione S-transferase $\pi$ and $\mu$ and did not detect glutathione $S$-transferase $\alpha$ in normal colon using an immunoperoxidase staining procedure. We used an alkaline phosphatase anti-alkaline phosphatase staining method, which is generally more sensitive than immunoperoxidase methods. Peters et $a l^{1325}$ also reported that glutathione S-transferase $\pi$ is the most frequently identified form of glutathione S-transferase in normal colon. Generally those xenobiotic enzymes that are expressed in normal colon are present in small quantities (our finding of patchy focal staining of surface epithelium would support this) and it has been suggested ${ }^{13}$ that the low level of expression of biotransformation enzymes in normal colon could result in a critically low detoxification value, and hence increase the chances of carcinogenesis taking place in this tissue.

There have been no extensive studies of xenobiotic metabolising enzyme expression in colonic adenomas. We found frequent expression of al the xenobiotic metabolising enzymes studied in colonic adenomas showing that an increase in the expression of these enzymes is a comparatively early molecular event during the development of colonic neoplasia and suggests that their expression may be important at the adenoma stage of colonic neoplasia.

Although there have been no previously reported immunohistochemical studies of cytochrome P450 or epoxide hydrolase in colonic carcinomas, there have been several biochemical studies of xenobiotic metabolising enzymes in colonic carcinomas. Western blot analysis by de Waziers $e t a l^{22}$ failed to detect the presence of cytochromes P450 1A1, 1A2, 2C8-10, and 2E1. In contrast, we were able to show the presence of a member of the cytochrome P450 1A family in $75 \%$ of colon carcinomas studied. Moreover, cytochrome $\mathrm{P} 450 \mathrm{1Al}$ associated mono-oxygenase activity (ethoxyresorufin 0 -deethylase) has been found in a small group of colon carcinomas. ${ }^{2}$ Cytochrome P450 3A was detected by de Waziers, ${ }^{22}$ and our own findings, that $61 \%$ of colon carcinomas express this family of cytochrome P450, are in agreement.

There has been only one report that has identified epoxide hydrolase in colonic carcinomas, ${ }^{22}$ by western blot analysis. The high frequency of expression of epoxide hydrolase seems to be a fairly general phenomenon of carcinomas as we have also identified frequent expression of epoxide hydrolase in carcinomas of the breast ${ }^{20}$ and liver. ${ }^{26}$

The expression in colonic carcinomas of different forms of glutathione S-transferase has been investigated in several biochemical studies. All reports using 1-chloro-2,4-dinitrobenzene as a substrate for total glutathione S-transferase activity have pointed to the presence of glutathione S-transferase activity in homogenates of colonic carcinomas. ${ }^{12222325}$ Western blots have shown glutathione $S$-transferase $\pi$ to be the form most frequently present. ${ }^{24}$ This finding is supported by the results of Howie et al, ${ }^{23}$ who used a radioimmunoassay to measure the activity of glutathione S-transferase $\pi$ expression. These data must be interpreted cautiously, however, in view of our findings that glutathione S-transferase $\pi$ is present in normal colonic epithelium and also in chronic inflammatory cells, which are often found as part of colonic carcinomas. We, however, found glutathione S-transferase $\alpha$ to be the most frequently expressed form of glutathione S-transferase in colon carcinomas. This is in contrast with Moorghen et al, ${ }^{1}$ who reported the presence of glutathione S-transferase $\pi$ in $100 \%$ of samples, and glutathione S-transferase $\alpha$ in only $10 \%$ of tumour samples, by immunohistochemistry with an immunoperoxidase staining method. As shown above, direct comparison between the different types of investigation used is not possible and only immunohistochemical techniques provide direct demonstration that the tumour cells do indeed contain xenobiotic metabolising enzymes.

In conclusion, we found normal colonic mucosa to be characterised by a low frequency of expression of various xenobiotic metabolising enzymes, with cytochrome P450 1A being undetectable. In contrast, colonic adenomas were found to exhibit a very high frequency of expression of specific forms of cytochrome P450, epoxide hydrolase, and glutathione S-transferase. The overall phenotypic expression of different xenobiotic metabolising enzymes in colonic carcinomas is complex. The frequent expression of the various xenobiotic metabolising enzymes may contribute to the anticancer drug resistance that is characteristic of carcinoma of the colon, ${ }^{27} 28$ and also to chemical carcinogenesis in the colon as these enzymes can metabolise both exogenous ${ }^{10}$ and endogenous ${ }^{29}$ compounds, which are implicated in the development of colon cancer.

This work was funded by grants from The Scottish Home and Health Department and Grampian Health Board, and RJW was supported by an SERC-CASE award from The Wellcome Foundation.

1 Moorghen M, Cairns J, Forrester LM, Hayes JD, Hall A, Cattan AR, et al. Enhanced expression of glutathione Stransferases in colorectal carcinoma compared to nonneoplastic mucosa. Carcinogenesis 1991; 12: 13-7.

2 Mekhail-Ishak K, Hudson N, Tsao M-S, Batist G. Implications for therapy of drug-metabolizing enzymes in human tions for therapy of drug-metabolizing enzzm

3 Kawajiri K, Fujii-Kuriyama Y. P450 and human cancer. $\mathcal{F p n} \mathcal{F}$ Cancer Res 1991; 82: 1325-35.

4 Rosenberg DW. Tissue-specific induction of the carcinogen inducible cytochrome P450 isoform, P4501A1, in colonic epithelium. Arch Biochem Biophys 1991; 284: 223-6.

Stralka DJ, Strobel HW. Cytochrome P450 activity and distribution in the human colon mucosa. Cancer 1989; 64 2111-6.

6 Le Blanc GA, Waxman DJ. Interaction of anticancer drugs with hepatic monooxygenase enzymes. Drug Metab Rev 1989; 20: 395-439.

7 Powis G, Prough RA, eds. Metabolism and action of anticancer drugs. London: Taylor and Francis, 1987.

8 Gonzalez FJ. Molecular genetics of the P-450 superfamily. Pharmacol Ther 1990; 45: 1-38.

9 Ioannides C. Induction of cytochrome P450I and its influences in chemical carcinogenesis. Biochem Soc Trans 1990; 18: in -4 .

10 Guengerich FP. Oxidation of toxic and carcinogenic chemicals by human cytochrome P-450 enzymes. Chem Res Toxicol 1991; 4: 391-407. 
11 Guengerich FP. Roles of cytochrome P-450 enzymes in chemical carcinogenesis and cancer chemotherapy. Cancer Res 1988; 48: 2946-54

12 Kaminsky LS, Fasco MJ. Small intestinal cytochromes P450. Crit Rev Toxicol 1992; 21: 407-22.

13 Peters WHM, Kock L, Nagengast FM, Kremers PG. Biotransformation enzymes in human intestine: critical low transformation enzymes in human intestin

$14 \mathrm{Lu} \mathrm{AYH,} \mathrm{Miwa} \mathrm{GT.} \mathrm{Molecular} \mathrm{properties} \mathrm{and} \mathrm{biological}$ functions of microsomal epoxide hydrase Ann Rev Pharmacol Toxicol 1980; 20: 513-31.

15 Board P, Coggan M, Johnston P, Ross V, Suzuki T, Webb G. Genetic heterogeneity of the human glutathione transferases: a complex of gene families. Pharmacol Ther 1990; 48: 357-69.

16 Black SM, Wolf CR. The role of glutathione-dependent enzymes in drug resistance. Pharmacol Ther 1991; 51: 139-54.

17 Murray GI, Foster CO, Barnes TS, Weaver RJ, Ewen SWB, Melvin WT, et al. Expression of cytochrome P450IA in breast cancer. Br 7 Cancer 1991; 63: 1021-3.

18 Shaw PM, Barnes TS, Cameron D, Engeset J, Melvin WT, Omar G, et al. Purification and characterization of an anticonvulsant-induced human cytochrome P-450 catalysinticonvulsant-induced human cytochrome P-450 catalys-

19 Barnes TS, Burke MD, Melvin WT. Differences in adult and foetal human cytochrome P-450 forms recognized by monoclonal antibodies with specificity for the P450III family. Biochem f 1989; 260: 635-45.

20 Murray GI, Weaver RJ Paterson PJ, Ewen SWB, Melvin WT, Burke MD. Expression of xenobiotic metabolising enzymes in breast cancer. 7 Pathol 1993; 169: 347-53.

21 Cordell JL, Falini B, Erber WN, Ghosh AK, Abdulaziz Z,
Macdonald S, et al. Immunoenzymatic labeling of monoclonal antibodies using immune complexes of alkaline phosphatase and monoclonal anti-alkaline phosphatase (APAAP Complexes). $f$ Histochem Cytochem 1984; 32: 219-29.

22 de Waziers I, Cugnenc PH, Berger A, Leroux J-P, Beaune PH Drug-metabolizing enzyme expression in human normal, peritumoral and tumoral colorectal tissue samples. peritumoral and tumoral

23 Howie AF, Forrester LM, Glancey MJ, Schlager JJ, Powis G, Beckett GJ, et al. Glutathione S-transferase and glutathion peroxidase expression in normal and tumour human tissues. Carcinogenesis 1990; 11: 451-8.

24 Hayes PC, Harrison DJ, Bouchier IAD, McLellan LI, Hayes JD. Cytosolic and microsomal glutathione S-transferase soenzymes in normal human liver and intestinal epithelium. Gut 1989; 30: 854-9.

25 Peters WHM, Nagengast FM, Wobbes T. Glutathione Stransferases in normal and canerous human colon tissue. Carcinogenesis 1989; 10: 2371-4.

26 Murray GI, Paterson PJ, Weaver RJ, Ewen SWB, Melvin WT, Burke MD. The expression of cytochrome P450, epoxide hydrolase and glutathione S-transferase in hepatocellular carcinoma. Cancer 1993; 71: 36-43.

27 Graham MA, Riley RJ, Kerr DJ. Drug metabolism in carcinogenesis and cancer chemotherapy. Pharmacol Ther 1991; 51: 275-89.

28 Young RC. Drug resistance: the clinical problem. In: Ozols $\mathrm{RF}$, ed. Drug resistance in cancer therapy. Boston: Kluwer Academic Publishers, 1989: 1-12.

29 Hill MJ. Bile flow and colon cancer. Mutat Res 1990; 238: 